\title{
LA EDUCACIÓN PUESTA A PRUEBA \\ EN UN ESPACIO DE RECLUSIÓN
}

\author{
EDUCATION PUT \\ TO THE PRISON TEST
}

\section{A EDUCAÇAO FACE \\ À DETENÇAO}

\begin{abstract}
Gilles Chantraine
Centro de Estudios y de INVESTIGACIÓN SOCIOLÓGICA y ECONÓMICA DE LILLE (CLERSE - CNRS, UMR 8019)

UNIVERSIDAD DE LILLE 1, FRANCIA
\end{abstract}

Nicolas Sallée

INSTITUCIONES Y DINÁMICA HISTÓRICA DE LA ECONOMÍA, (IDHE - CNRS, UMR 8533)

Universidad de París Ouest Nanterre la Défense, Francia

RESUMEN: Recién llegados al paisaje carcelario francés, los establecimientos penitenciarios para menores (EPM) son fruto de la voluntad de convertir los espacios de reclusión destinados a jóvenes de entre 13 y 18 años en espacios propiamente "educativos", al objeto de dar respuesta a la falta de continuidad socioeducativa de los menores presos de los quartiers mineurs ubicados en las prisiones de adultos. Basada en una investigación monográfica realizada en dos EPM que mezcla observaciones directas de la vida cotidiana de la reclusión con entrevistas semiestructuradas hechas al conjunto de actores del EPM. Esta contribución está basada en una investigación monográfica hecha en dos EPM, que mezcla observaciones directas de la vida cotidiana de la reclusión con entrevistas semidirectivas realizadas al conjunto de actores del EPM; su objetivo es analizar la forma adoptada por las prácticas educativas en estos establecimientos y su entrelazamiento con el orden penitenciario. Una vez recorda- dos algunos elementos de contexto relativos a las recientes transformaciones de la justicia de menores en Francia, propondremos una mirada simétrica de las prácticas de los educadores de la PJJ (Protección Judicial de la Juventud) y de los vigilantes penitenciarios.

Este análisis simétrico nos llevará a demostrar que, aun poniendo de manifiesto una apertura relativa de la institución carcelaria, el EPM sigue marcado por una supremacía de las lógicas securitarias sobre las lógicas educativas, que dibuja una articulación original entre ambas lógicas: en el EPM ya no se trata únicamente de constreñir los cuerpos de los presos a someterse al orden penitenciario, sino también de una labor de movilización de las subjetividades reclusas mediante un trabajo "educativo" de persuasión sobre la pertinencia del orden penitenciario.

PALABRAS CLAVE: Prisión; menores; educación; disciplina; orden; responsabilización. 
ABSTRACT: Prisons for Minors (PM) are relatively new in the French prison landscape correctional system. Their appearance reflected a political desire to turn incarceration spaces for youths aged 13 to 18 into properly "educational" spaces, in order to address the lack of socio-educational attention that minor prisoners were suffering in juvenile units in adult prisons.

Based on a monographic study conducted within two PMs, combining direct observation of everyday prison life and semi-structured interviews with all PM actors, this contribution aims to analyse the form taken by educational practices in these establishments, and examine how they are weaved into the penitentiary order. After providing some context relating to the juvenile justice system in France, we will examine the practices of PJJ tutors (Protection judiciaire de la jeunesse / Youth Judicial Protection Service) in symmetry with those of prison guards.

This symmetrical analysis will lead us to show that, although PMs testify to a decompartmentalisation in relation to the prison institution, they are still marked by the dominance of security rationales over educational rationales. This dominance also testifies to an original connection between these two rationales: in PMs, it is not solely a matter of forcing the bodies of prisoners to submit to the penitentiary order; it is also an effort to enlist cloistered subjectivities through an "educational" work of persuasion concerning the validity of the penitentiary order.

KEY WORDS: Prison; minors; education; discipline; order; responsibilisation.
RESUMO: Relativamente nova na paisagem prisional francesa, a abertura de estabelecimentos prisionais para menores (EPM) surgiu da vontade política de fazer dos espaços de reclusão reservados aos jovens entre os 13 e os 18 anos lugares "educativos", como forma de resposta à falta de acompanhamento socioeducativo da qual sofrem os menores detidos nas alas situadas nas prisões para adultos.

Esta contribuição, baseada numa pesquisa monográfica realizada em dois EPM, através da observação directa do quotidiano e de entrevistas semi-dirigidas com todos os actores dos EPM, propõe uma análise da forma como foram pensadas as práticas educativas nesses estabelecimentos e como foram articuladas com a lógica prisional. Depois de lembrar alguns elementos de contexto relativos às transformações recentes da justiça de menores em França, propomos um olhar simétrico sobre as práticas dos educadores da PJJ (Proteção judiciária da juventude) e dos guardas prisionais.

Esta análise simétrica permitir-nos-á demonstrar que, apesar de ter origem numa certa abertura relativa à instituição prisional, o EPM continua impregnado de uma supremacia da lógica de segurança sobre a lógica educativa, realizando uma articulação original entre as duas: no EPM, não se trata somente de constranger os corpos dos detidos a submeteremse à ordem prisional, mas também de fazer um esforço para "engajar" as subjectividades reclusas através de um trabalho "educativo" de persuasão quanto à legitimidade da ordem prisional.

PALAVRAS CHAVE: Prisão; menores; educação; disciplina; ordem; responsabilidade. 


\section{Introducción}

Recién llegados al paisaje carcelario francés, los establecimientos penitenciarios para menores (EPM) son fruto de la voluntad de convertir los espacios de reclusión destinados a jóvenes de entre 13 y 18 años en espacios propiamente "educativos", al objeto de dar respuesta a la falta de continuidad socioeducativa de los menores presos de los quartiers mineurs ${ }^{1}$, ubicados en las prisiones de adultos ${ }^{2}$. En pos de este objetivo, los EPM cuentan con personal de vigilancia del establecimiento penitenciario al que se suman un buen número de profesores de la Educación Nacional, personal sanitario y educadores de la Protección Judicial de la Juventud (PJJ).

A diferencia de los profesores y del personal sanitario, quienes, para desempeñar sus funciones, disponen en el EPM de sus propios espacios ubicados en edificios claramente identificados ("polo escolar", "polo de salud"), los educadores PJJ están obligados a trabajar colaborando más estrecha y directamente con los vigilantes penitenciarios en la vida diaria de la reclusión. A su vez, el personal penitenciario ha de organizar el cotidiano carcelario con los educadores PJJ (o, al menos, bajo su mirada). En el día a día, esta obligación recíproca se encarna en la intervención conjunta de vigilantes y educadores en las diferentes unidades de vida que componen el espacio de reclusión 3 . Se supone, por lo tanto, que educadores y vigilantes deben trabajar "en binomio", expresión consagrada en la presentación formal de los EPM y que se traduce en la vinculación de los principios securitarios de la administración penitenciaria con las necesidades educativas imprescindibles para la "resocialización" de los presos.

Dependiendo de si se miran desde el punto de vista propio de la PJJ o desde el de la administración penitenciaria, los envites y problemas que plantea el proyecto "EPM" son al mismo tiempo diferentes y similares. Para la administración penitenciaria, el "proyecto EPM" y sus aspiraciones educativas se perciben como la promesa de un dispositivo carcelario capaz de concretar el "mito fundacional de la pena de prisión" que, al menos en el orden discursivo, permite transformar el "mal" del encierro en una pena de prisión "buena" (Faugeron y Le Boulaire, 1992). Para la administración penitenciaria, los EPM constituyen además un escaparate que ha de lucir tanto más cuanto que su apertura se inscribe en la tentativa, reivindicada por el gobierno francés desde octubre de 2006, de someter el funcionamiento de las prisiones francesas a las "Reglas penitenciarias europeas" adoptadas en enero de ese mismo año por el Comité de Ministros del Consejo de Europa.

Desde la perspectiva de la PJJ, el hecho de que algunos de sus miembros tengan que volver a implicarse en los espacios de reclusión ${ }^{4}$ debilita una de las bases simbólicas de su identidad. En efecto, la PJJ se escindió como departamento autónomo del Ministerio de Justicia (con el nombre, entonces, de Educación vigilada y, a partir de 1990, de PJJ) tras la II Guerra Mundial, emancipándose así de la tutela de la administración penitenciaria. Así, pues, a finales de la década de 1970, los educadores de la Educación vigilada abandonaron los recintos penitenciarios donde estaban encarcelados los menores, en nombre de una reivindicada incompatibilidad entre educación y constricción del encierro -penitenciario o no, más adelante volveremos sobre esto. Por lo tanto, el proyecto de apertura de los EPM se inscribe explícitamente en un movimiento de reforma de las instituciones educativas destinadas a los menores delincuentes. Al promover la adecuación entre la constricción penal en un medio cerrado y las responsabilidades educativas, la puesta en marcha de los EPM encarna un proceso de redefinición de los contornos de la acción educativa que, a juicio de diferentes personalidades del ámbito de la PJJ, permitiría garantizar simultáneamente neutralización y corrección educativa de los jóvenes delincuentes (Sallée, 2009).

En este marco, y una vez recordados algunos elementos de contexto en torno a las recientes transformaciones de la justicia de menores en Francia, convendría preguntarse cómo se están reconfigurando las prácticas educativas de estas nuevas prisiones. A este objeto será necesario prestar una atención simétrica a los educadores de la PJJ y a los vigilantes penitenciarios. Esta simetría es tanto más necesaria cuanto que, susceptible de ser reivindicada como una competencia personal antes que profesional, la acción educativa no podría ser a priori una acción reservada a los educadores. En efecto, los vigilantes de la administración 
penitenciaria también pueden reivindicar su labor educativa ya sea recurriendo a competencias personales que, como cualquier otra persona, pueden dominar o no, ya desde una definición de su trabajo de vigilantes como igualmente compuesto de una parte educativa ligada a las competencias relacionales exigidas por el desempeño de su actividad.

\section{Metodología}

Precedidos por una presentación de las recientes transformaciones experimentadas por la justicia de menores en Francia, los resultados que se expondrán a continuación se basan en la combinación de datos empíricos recogidos en el seno de dos EPM (Chantraine, Dir., 20115) en los que las características de la población carcelaria traducen realidades globalmente similares a los datos nacionales (DPJJ, 2012)6 ${ }^{6}$. Cada una de estas investigaciones se apoya en la realización de alrededor de cuarenta días de observación directa y en una cincuentena de entrevistas semidirectivas realizadas a todos los actores del espacio de reclusión, desde los profesionales a los presos. Pese a algunas importantes diferencias de funcionamiento entre estos dos EPM, desde su arquitectura a la composición sociológica de los equipos profesionales que trabajan mano a mano en su seno, nuestro análisis se asienta en la integración de datos al objeto de proponer una reflexión en torno al envite transversal de estos establecimientos: la forma en la que se estructuran los territorios profesionales de vigilantes y educadores, a través de las prácticas de regulación educativas, disciplinarias y securitarias del comportamiento de los reclusos. Los nombres y apellidos de las personas entrevistadas han sido evidentemente modificados $y$, a fin de respetar el anonimato en un microcosmos cerrado y restringido donde la gente se conoce y se observa intensamente, hemos optado asimismo por no mencionar ni las edades ni los tipos de carrera (profesional o delictiva) de los participantes.

\section{El contexto: transformaciones recientes en la justicia de menores en Francia}

Desde la década de 1990 y particularmente desde 1993 (año de inicio de una alternancia política favorable a los partidos de derechas), la delincuencia juvenil pasó a ser una preocupación política central. Esta mutación se puso de manifiesto en un aumento repentino de las estadísticas oficiales sobre delincuencia juvenil. Pero este aumento no respondía tanto a una transformación sustancial de los comportamientos de los menores, como a una modificación de la respuesta penal que se les daba (Aubusson de Cavarlay, 1999, Mucchielli, 2010).

El número de menores denunciados por los servicios de policía y gendarmería se disparó, de hecho, a comienzos de la década de 1990. Mientras de 1977 a 1992, ese número pasó de 82.151 a 98.864, esto es, una subida de 20,4\%, el aumento entre 1992 y 2001 fue de 79\%, alcanzando la cifra de 177.017 denunciados en 2001. Desde entonces ese número no ha dejado de crecer alcanzando las 214.612 denuncias en 2009 -es decir, una subida de 17,5\% entre 2001 y 2009. Esta tendencia ha ido acompañada de una serie de discursos políticos y mediáticos alarmistas sobre el supuesto "estallido" de una delincuencia juvenil, alimentando la difusión masiva de un "sentimiento de inseguridad" entre la población (Robert y Pottier, 2004). Tales transformaciones han provocado, lógicamente, un incremento de la actividad de las jurisdicciones para menores, en parte absorbida por el mayor papel asumido por el ministerio público en la regulación de los flujos de menores delincuentes (Milburn, 2009). Mientras crecía el recurso a las medidas conocidas como "alternativas a las persecuciones", en el caso de los menores delincuentes se fue imponiendo el principio de una intervención judicial "en tiempo real", preparada para controlar al nuevo enemigo de las políticas penales: el "sentimiento de impunidad" de estos nuevos menores delincuentes infrasocializados (Mucchielli, 2000).

¿Cuál ha sido la evolución del número de menores encarcelados en este contexto? En primer lugar, se pone efectivamente de manifiesto un aumento importante del número anual de sentencias de cárcel impuestas a menores durante la década de 1990: este pasa de 2.661 en 1994 a 4.326 en 1999, es decir, una subida de $38,5 \%$. Este aumento es sin embargo posterior, a una fuerte disminución a finales de la década de

[ 32 ] GILLES CHANTRAINE, NICOLAS SALLÉE

SIPS - PEDAGOGIA SOCIAL. REVISTA INTERUNIVERSITARIA [1139-1723 (2013) 22, 29-42] TERCERA ÉPOCA 
$1980^{7} \mathrm{y}$, de hecho, las tasas de menores encarcelados nunca han vuelto a alcanzar, ni siquiera hoy, los niveles récord de finales de las décadas de 1960 y 1980. A finales de la década de 1990, el número anual de sentencias de cárcel para menores conoció, por lo tanto, un primer descenso de 1999 a 2001 (pasando de 4.326 a 3.283,-24,1\%) y un segundo descenso de 2002 a 2010 (pasando de 3.839 a 3.107, -19\%). Si en la década de 1990 el aumento de menores presos parece "responder" esencialmente al crecimiento continuo del número de menores denunciados por los servicios de policía y gendarmería (Sicot, 2009), ¿cómo entender el descenso, desde 1999, de menores encarcelados, mientras el número de menores denunciados no deja de crecer ni los discursos políticos de firmeza frente a la delincuencia juvenil de multiplicarse?

Para entenderlo, conviene detenerse en una transformación de suma importancia que el ámbito de la justicia de menores lleva experimentando desde mediados de la década de 1990: las transformaciones cualitativas de los dispositivos de internamiento no penitenciario de los menores delincuentes. Mientras se extendían los discursos alarmistas sobre la delincuencia juvenil fueron sucesivamente creados, en 1996 y por la derecha, las unidades de Encuadramiento Educativo Reforzado (UEER), transformadas con el regreso de la izquierda al poder en 1998 en Centros Educativos Reforzados (CER) y, más tarde, con la vuelta de la derecha al gobierno en 2002, en Centros Educativos Cerrados (CEF). En este marco, el número anual de menores destinados a este tipo de dispositivos cerrados de internamiento (CER + CEF) experimenta un incremento significativo, pasando de 1.316 en 2004 a 2.241 en $2010(+41,2 \%)$. Este aumento se explica principalmente por la evolución del número anual de menores ubicados en CEF, que pasa de 159 en 2004 a 1.240 en $2010(+87,1 \%)$, mientras el número anual de menores ubicados en CER se mantiene relativamente estable (+3,6\%). De esta suerte, la proporción de menores asignados a un CEF respecto al número total de menores asignados a algún espacio en nombre del derecho penal pasa de 3,1\% en 2004 a 19,1\% en 2010. La tendencia debería confirmarse nítidamente en los próximos años, habida cuenta de que, avalado por un reciente informe del Senado sobre la eficacia del dispositivo (Peyronnet y Pillet, 2011), el Ministerio de Justicia acaba de anunciar la apertura de una veintena de nuevos CEF a lo largo de los próximos años. Estos datos son esenciales para entender los envites que atraviesa el encarcelamiento de menores en Francia. En efecto, la novedad no reside tanto en el encarcelamiento de menores en sí mismo, como en la voluntad de convertir los espacios de reclusión en espacios educativos.

En tanto espacios de aplicación de una pena privativa de libertad, los EPM se sitúan entonces en el extremo de un continuo de dispositivos asentados en la idea de una "educación en situación de reclusión". Conviene describir y analizar, por consiguiente, la forma en que los profesionales del EPM-empezando por los educadores y pasando, después, a los vigilantes- recurren a diversas concepciones educativas, y la manera en que estas concepciones y prácticas educativas se imbrican e hibridan con la disciplina carcelaria y la producción del orden penitenciario.

\section{Educadores en prisión}

Si en los EPM, los educadores intervienen efectivamente entre los muros, una de sus preocupaciones principales es acercarse a los jóvenes reclusos más allá de los muros: el servicio educativo del EPM se suele percibir y describir, efectivamente, como uno de los elementos de una red sociopenal más amplia y los educadores se definen en su mayoría como un eslabón de la cadena judicial, desde el magistrado que decide el ingreso en prisión del joven al educador externo que sigue su trayectoria. En este marco, los educadores se consideran intermediarios entre el interior y el exterior del EPM. Esta mirada extracarcelaria de los educadores sobre la trayectoria de los jóvenes reclusos se dirige tanto a su historia anterior a la reclusión como a su orientación a partir de ella, en base a un eventual proyecto de salida. Desde la perspectiva de este trabajo orientado hacia la futura salida del menor, los educadores se centran sobre todo en la tarea de hacerle comprender que no ha de hacerse únicamente cargo de un entorno cerrado, sino también de un entorno externo más denso: el entorno del que procede y al que regresará una vez finalizado su período de reclusión. 
Pero la misión asignada a los educadores que intervienen en el EPM no termina ahí. En efecto, junto a los vigilantes penitenciarios, los educadores se ven asimismo obligados a implicarse en el cotidiano del medio carcelario para construir y sostener en este último unos espacios de naturaleza propiamente educativa. El objetivo perseguido es promover la construcción de una continuidad entre el ritmo carcelario del EPM y un ritmo social "normal", a fin de reducir los riesgos de desocialización consecutivos a una ruptura radical con el exterior. Esta concepción educativa es la que, desde mediados de la década de 1990, ha permitido a diferentes actores de la dirección de la PJJ justificar la necesidad de recurrir a unas estructuras de responsabilización asentadas en un encuadramiento educativo reforzado (centros educativos reforzados, centros educativos cerrados). A partir de una crítica de la focalización de muchos educadores en la primacía de la construcción de relaciones duales con los menores, se ha tratado de legitimar un pensamiento educativo de lo "colectivo"8. A partir de la crítica, desde 1998, de la embrutecedora ociosidad padecida por los jóvenes de los quartiers mineurs de las prisiones, dos viejos educadores, Jean-Louis Daumas y Manuel Palacio, señalaban la necesidad de "[dotar] de consistencia a todas esas horas que discurren a lo largo del día", de "[estructurar] la reclusión para convertirla en una palanca en vez de en un reloj de arena que, como si fuera un búmeran, devuelve al joven su propia imagen devaluada" (Daumas y Palacio, 1998, p.22). Sin embargo, esta concepción educativa, a veces denominada "hacer juntos" (Botbol y Choquet, 2010), no es ni mucho menos unánimemente compartida en el EPM. En su seno, algunos educadores denuncian, efectivamente, el escaso lugar que este tipo de establecimientos deja a la posibilidad de llevar a cabo lo que a su juicio sería un "verdadero seguimiento educativo" de los presos. Así, pues, y aun a riesgo de ignorar, de caer en eufemismos o, lo que a veces viene a ser lo mismo, de asumir la notoria violencia estructural de los quartiers mineurs, algunos educadores terminan envidiando las condiciones de ejercicio de la función educativa en tales espacios.

No creo que el EPM sea un espacio educativo. Hay dos formas de verlo: están los de la cultura del acogimiento y, por consiguiente, de lo colectivo, y los de la cultura del medio abierto y, por consiguiente, de la responsabilización individual. Yo pertenezco a la cultura del medio abierto, así que aquí no son amistades lo único que me granjeo [...] Al final he llegado a la conclusión de que podría trabajar perfectamente en un quartier mineurs. Sé que hay argumentos en contra de ellos... pero creo que en los quartiers mineurs el marco es tan claro, que los menores se meten como locos en los espacios educativos propuestos, porque son menos $y$, en cualquier caso, mucho más reconocibles como tales. $Y$ de repente esto se convierte en agua bendita para el trabajo de los educadores, para entablar conversaciones (Christine, educadora).

La justificación de esta educadora de la necesidad de un marco carcelario "claro" coincide con la crítica según la cual los EPM alimentarían una doble confusión de categorías. Confusión, en primer lugar, de orden profesional, dado el riesgo de disolución de la identidad educativa en una identidad "EPM" que haría perder la especificidad de la PJJ. De orden penal, en segundo lugar, pues pone directamente en tela de juicio las condiciones de reclusión propias del EPM. Estructuradas en base a una sobreactividad programada de la mañana a la noche y basadas en las características tradicionales de una prisión (separación y segregación espaciales, inercia por redundancia de un cotidiano con poco margen para las iniciativas innovadoras, incertidumbre respecto a los tiempos de reclusión, régimen disciplinario, hipervigilancia, etc.), las condiciones de reclusión son, sin embargo, denunciadas como "demasiado flexibles"... Acusadas de alejar el EPM de una "verdadera prisión", tales condiciones impedirían la emergencia de una "toma de conciencia" del delincuente respecto a la gravedad de los hechos delictivos que determinaron su internamiento. Esta idea según la cual el EPM no sería suficientemente aflictivo rebela una concepción del trabajo educativo como un trabajo de "responsabilización" asentado en la dimensión supuestamente estructurante para la personalidad de los jóvenes delincuentes del recuerdo de sus obligaciones penales 9 -aquí, el fin justificaría los medios.

[ 34 ] GILLES CHANTRAINE, NICOLAS SALLÉE

SIPS - PEDAGOGIA SOCIAL. REVISTA INTERUNIVERSITARIA [1139-1723 (2013) 22, 29-42] TERCERA ÉPOCA 


\section{Vigilantes "educadores"}

El resurgimiento puntual, aunque frecuente, de esta concepción educativa en lo cotidiano ilumina la forma en que la prisión pone a prueba la identidad profesional de los educadores. Esta puesta a prueba está especialmente ligada a la posición adoptada en estas nuevas prisiones por los vigilantes penitenciarios. A diferencia de los educadores, cuya primera misión consiste en producir trayectorias socioeducativas más allá de los muros, los vigilantes deben ocuparse, en primer lugar, de la producción del orden intramuros. Al igual que en la cárcel de adultos, los vigilantes recurren cotidianamente a un sistema informal y de "toma y daca" para regular los comportamientos individuales y gestionar el ambiente del espacio de reclusión ${ }^{10}$. Pero en una prisión para menores este sistema puede convertirse en una oportunidad, para aquellos que deseen alejarse de su papel tradicional -y estigmatizado- de "carcelero", de dar al mismo un contenido semántico educativo. Muchos son, de hecho, quienes explican haber elegido el EPM para dar un "sentido a su profesión", después de haber trabajado en cárceles de preventivos y de cumplimiento para adultos ${ }^{11}$. Este tipo de postura, que participa de una forma de revalorización del papel tradicional del vigilante, es susceptible de inscribirse en un recorrido profesional o personal donde la sensibilidad hacia los "jóvenes en riesgo social" y hacia la "miseria social" viene a combinarse con cierta concepción de la profesión de vigilante. Así lo señala Michel, al que entrevistamos en vísperas de su jubilación:

Lo hice por decisión propia, porque tenía ganas de cambiar... Me estaba cansando un poco de lo que había elegido al principio y quería abrirme un poco. Después me di cuenta de que en la vida corriente hay muchos niños en riesgo social, mucha miseria social. En mi caso, entre comillas y modestamente, a mis dos hijos les ha ido bastante bien. Creo haberles dado una educación más o menos correcta. Así que me centré un poco en esto y trabajé, profundicé en la cuestión, y lo he hecho lo mejor que he podido hasta hoy. No digo que haya sido un éxito total, no, pero creo que he aportado cosas y que, a cambio, he recibido pequeños... retornos positivos, chavales que me han escrito para darme las gracias (Michel, vigilante).

Al insistir en la importancia de su experiencia personal y en la educación de sus hijos, Michel expone una de las reivindicaciones centrales de algunos vigilantes, según la cual las tareas educativas no estarían exclusivamente reservadas a una categoría profesional. Las críticas hacia sus "colegas" de la PJJ, a quienes suelen tachar de "laxistas" y de participar en la transformación de la prisión en un "Club Med" o en un "hotel de cuatro estrellas", no son óbice para que algunos vigilantes se erijan en los verdaderos educadores del EPM:

Aquí los vigilantes hacemos muchas veces de... bueno, no debería decir esto, pero a menudo somos más educadores que el educador. Mira ahí, ¿̇es? [indica con un gesto de la mano la ausencia del educador en la oficina], si un chico llama pues somos nosotros los que le vamos a ver, a hablar con él; si alguno se pasa de la raya, somos nosotros quienes vamos a ponerle en su sitio [...]. Un educador pone en el sitio [con un gesto seco de la mano, de arriba a abajo], recuerda los límites (Bruno, vigilante).

Esta concepción de su papel se encarna así en los vigilantes en la superposición de un discurso "educativo" y de un hiper reglamentarismo basado en la idea de que la imposición de unos "límites" claros y rígidos es la condición sine qua non de un "buen" trabajo educativo.

La disciplina es importante y solemos olvidar que si escuchas demasiado a un chaval, si no le marcas unos límites, tenderá a hacer cualquier cosa. Justamente porque no se le han marcado unos límites. [...] Quienes hemos recibido una educación no nos damos cuenta de que un chaval que no ha sido educado así, al que nunca se le ha dicho que "no", al que nunca se le han marcado unos límites, puede... bueno, puede estar completamente desorientado, vaya. [...] Yo digo "no" a la elección de actividades, no se debería dejar elegir, porque marcar unos límites a estos chicos significa darles, imponerles un programa (Jean-Claude, vigilante principal).

LA EDUCACIÓN PUESTA A PRUEBA EN UN ESPACIO DE RECLUSIÓN [ 35 ] SIPS - PEDAGOGIA SOCIAL. REVISTA INTERUNIVERSITARIA [1139-1723 (2013) 22, 29-42] TERCERA ÉPOCA 
Según los vigilantes del EPM, con los jóvenes que "han perdido todos los límites" convendría retomar un trabajo educativo y de socialización allí donde los padres han fracasado. Esta concepción educativa propone la visión virtuosa de las prácticas del "toma y daca", que vendrían a sancionar positiva o negativamente a los internos en el día a día. En este sentido, las formas tradicionales del orden en el espacio de internamiento pueden ser entendidas como el resultado de un condicionamiento educativo fundado en el principio comportamental del palo y la zanahoria.

Pero los vigilantes no son los únicos que tienen esta concepción educativa: también hay muchos educadores que proclaman su supuesta eficacia. Esta concepción es efectivamente defendida por distintos actores del ámbito educativo que creen necesario reafirmar las "exigencias sociales" que pesan sobre los menores delincuentes, a fin de "transmitirles los valores y saber hacer necesarios para integrarse en una sociedad racionalizada" (Youf, 2000, p.110). Esta educación de orientación comportamentalista, que constituye uno de los fundamentos de los dispositivos de acogimiento constrictivo -CER, CEF-, se basa en la idea de un nuevo aprendizaje condicionado de los ritmos de una vida social "normal". La agenda y el reglamento asociado a ella se consideran herramientas educativas de importancia principal. Si algunos vigilantes no se ven acantonados en un papel de vigilancia pero sí legitimados para reivindicar la parte educativa de su misión es gracias a una articulación entre las susodichas virtudes educativas de la imposición de "unos límites" y lo descrito como necesidades pragmáticas de una gestión en términos de "toma y daca". Así es como los vigilantes se introducen en el terreno que los educadores sienten como exclusivamente suyo: el terreno educativo. La falta de reciprocidad, que ahora detallaremos, explica el dominio estructural de las lógicas securitarias sobre cualquier otra lógica de acción en el espacio de reclusión.

\section{5. "Medidas educativas" y supremacía penitenciaria}

Cuando las prácticas más informales de producción del orden parecen insuficientes, la dirección de los EPM promueve formas de sanción que permiten a los diferentes profesionales responder al comportamiento de un recluso eludiendo los procedimientos disciplinarios propiamente dichos y regulados por el derecho penitenciario. Estas sanciones suelen consistir en la privación de tiempos colectivos -comida en común, actividades deportivas o socioculturales- durante cierto tiempo, un día por lo general, para responder a un exceso por el que los profesionales no creen necesario abrir un procedimiento disciplinario -un insulto, una negativa a volver a la celda, un acto de desobediencia cualquiera.

Es preciso preguntarse seriamente por la denominación ordinaria de estas sanciones como "medidas educativas". En el discurso de sus promotores, estas medidas permitirían poner inmediatamente en su sitio a los jóvenes saltándose un procedimiento disciplinario -que a veces les parece largo-y cuyo punto débil es desconectar temporalmente el acto incívico cometido de la respuesta aportada por el profesional: esta sería la dimensión "educativa" de dichas medidas. Para defender este tipo de argumentos, la jerarquía penitenciaria suele recurrir, de nuevo, a la retórica familiar, apelando al tópico del sentido común educativo y a la figura del buen padre de familia, que justificarían una regulación más flexible de los altercados.

Alternativa al informe de incidente ${ }^{12}$, el estatuto y finalidad de la "medida educativa" pueden llegar a convertirse en objeto de vivas controversias entre educadores y vigilantes. En la "reunión binomio" de una unidad, los tres educadores presentes trataban de defender ante los vigilantes la pertinencia de sanciones alternativas al confinamiento en la celda, apoyándose en el ejemplo de un menor recientemente sancionado por la vigilante de unidad con una "medida educativa", por haberse negado a volver a su celda.

Virginie, educadora. Es como con lo de Sammy [el menor sancionado], podían habernos preguntado, ¿̇no? Es sanción o sanción, ¿̇no? Se les podría pedir un trabajo escrito sobre sus actos, por ejemplo, esto sería mucho más interesante.

Julie, vigilante. De todas formas, no lo harían.

[ 36 ] GILLES CHANTRAINE, NICOLAS SALLÉE

SIPS - PEDAGOGIA SOCIAL. REVISTA INTERUNIVERSITARIA [1139-1723 (2013) 22, 29-42] TERCERA ÉPOCA 
Virginie. iCon nosotros sí! Para eso estamos aquí. Hacerles escribir una cosa de 10 páginas, por ejemplo, algo sobre la violencia y todo eso, podría ser interesante; siempre sería mejor, en todo caso, que dejarles ver la tele todo el día.

(Diario de campo)

En este EPM, los educadores de la unidad en cuestión negaban colectivamente el carácter "educativo" de estos dispositivos de regulación del conflicto. Así se enfadaba una educadora con los vigilantes que presumen de educar mediante la práctica del confinamiento: "Resulta que una sanción no es automáticamente educativa, ese es el problema. Y para mí, el confinamiento no lo es. No es educativo. Los vigilantes lo llaman 'medida educativa', perdón pero me da la risa: es que eso no es educativo, no es educativo para nada". Se irritaba en balde, pues el contenido de las medidas educativas no se cambia nunca -o no, al menos, mientras duró nuestra investigación. Su denominación, sin embargo, sí ha evolucionado significativamente, deslizándose progresivamente hacia la noción de "medidas de buen orden", también llamadas "MBO". Este deslizamiento semántico que acentúa la naturaleza propiamente securitaria de este tipo de sanciones nos pone sobre la pista del engañabobos que estructura las controversias entre educadores y vigilantes del EPM, cuando estas tocan no al meollo del oficio de los educadores, sino al de los vigilantes: la seguridad.

Si el alcance de los debates crece y amenaza con alcanzar el monopolio de encuadramiento de los vigilantes, estos últimos disponen de un argumento de última instancia, al que recurren regularmente, y icuán eficaz!, para cortar en seco las controversias profesionales: el carácter penitenciario del establecimiento. En otras palabras, potencialmente la legitimación educativa de las prácticas de regulación del orden siempre puede suspenderse para anteponer las necesidades securitarias de la institución. Así sucedió, por ejemplo, tras un incidente ocurrido durante una sesión deportiva en la que un chaval escaló un muro del gimnasio del EPM y se puso a incitar e insultar al equipo de vigilantes allí presente. En respuesta al incidente, los vigilantes decidieron abrir un procedimiento disciplinario además de aplicarle una "medida educativa" para el resto del día13. Mientras los educadores presentes denunciaban que esto suponía una "pena doble" antieducativa y proponían formas alternativas de mediación para responder al incidente, los vigilantes no se arriesgaban a meterse en una controversia potencialmente peligrosa, conformándose con anteponer el imperativo de seguridad inherente a una situación donde se podía "armar una buena". Algunos días más tarde, un vigilante principal volvía a aludir a estas formas características de regulación de conflictos haciendo hincapié, mediante el calificativo temporal -"en un momento dado"-, en estos momentos-báscula durante los cuales los imperativos securitarios se anteponen a cualquier otra consideración:

Puede haber casos en los que se sumen CRI [informe de incidente] y medida educativa, porque el hecho de dejar al recluso en la celda es una medida de seguridad, por lo que yo incluso dejaría de llamarlo medida educativa; se trata de una medida que nos permite poner fin a un incidente y evitar que se reproduzca ya que sabemos que, si se le saca, el recluso repetirá los incidentes porque aún está caliente [...]. En un momento dado, estamos obligados a protegernos, proteger los bienes forma parte de nuestro cometido (Michel, vigilante principal).

Aunque este recurso solo se moviliza de manera puntual, siempre es movilizable, dibujando de esta forma la asimetría de las relaciones de fuerza institucionales que se inmiscuyen en las relaciones entre educadores y vigilantes. La administración penitenciaria adopta así una postura de cooperación bajo condición penitenciaria. De acuerdo a esta postura, se trata de asumir la parte educativa de la misión de vigilancia en el EPM en base a unas formas de reparto y de cooperación con el personal educativo, pero solo después de haber ajustado el funcionamiento del establecimiento al de una "prisión". La propia noción de "prisión" y lo que acarrea en cuanto a representaciones en términos de inercia institucional, se utiliza así para cortar de raíz con las controversias en torno a formas alternativas de organizar la reclusión. Su uso recurrente traduce, en última instancia, la supremacía de la administración penitenciaria en su capacidad de reproducir su funcionamiento ordinario.

LA EDUCACIÓN PUESTA A PRUEBA EN UN ESPACIO DE RECLUSIÓN [ 37 ] SIPS - PEDAGOGIA SOCIAL. REVISTA INTERUNIVERSITARIA [1139-1723 (2013) 22, 29-42] TERCERA ÉPOCA 


\section{La extensión de la responsabilización penal}

El hecho de que ninguna reivindicación sobre la organización de la reclusión sea capaz de prosperar produce algunas formas de desánimo e, incluso, de apatía entre los educadores. De acuerdo al análisis de Guy Bajoit (1988), esta forma "apática" de reacción ante el descontento ${ }^{14}$ se traduce en un "deterioro de la cooperación" y en una pérdida de adhesión a las finalidades de la actividad, [aprovechándose] el individuo "de su estatus" para hacer lo menos posible (Ibid., p. 332). A una relativa distancia del trabajo en "binomio", algunos educadores acaban convirtiéndose así, en el día a día, en los críticos pasivos y decepcionados de las modalidades de producción del orden propias de la administración penitenciaria.

Al mismo tiempo, la falta de implicación relativa de los educadores en las prácticas de producción del orden es percibida por muchos de ellos como aquello que les permite concentrarse en lo que, a su juicio, es el "verdadero" trabajo educativo: el seguimiento de la trayectoria individual de los menores presos y el objetivo de responsabilización -antes descrito- que lo acompaña. Así, pues, los educadores pueden desinteresarse de las relaciones de cooperación con sus "colegas" vigilantes sin que esto suponga una renuncia a las finalidades de su trabajo. La ambivalencia de esta lógica del desinterés, unas veces reactiva frente a la primacía de las lógicas securitarias y otras proactiva en defensa de su identidad profesional, acentúa la ambivalencia más general del posicionamiento de los educadores en el EPM. Si bien estas actitudes se ven efectivamente legitimadas por la constatación de una supremacía penitenciaria en la definición de las modalidades de producción del orden carcelario, también tienen el efecto rebote de legitimar dicha supremacía, desembocando en una forma de "malentendido bien entendido" (La Cecla, 2002), donde los educadores, incluso los más descontentos, pueden conformarse con esta situación de asimetría para encontrar en ella recursos de valorización de su profesionalidad.

Así, pues, en ciertas situaciones los educadores se implican en una lógica de investir educativamente las prácticas penitenciarias de producción del orden. Los educadores se limitan entonces a intervenir una vez las sanciones han sido impuestas por los vigilantes, recurriendo a una concepción responsabilizadora de la acción educativa para legitimar, al mismo tiempo, la eficacia del trabajo en binomio y la pertinencia educativa del orden penitenciario. Esto es lo que sucede regularmente en cualquiera de esos incidentes cotidianos y banales que amenizan la vida cotidiana del EPM. Un ejemplo: acusado por uno de los vigilantes principales del EPM de haber roto sus sábanas y sintiéndose víctima de una injusticia, un menor preso se negaba firmemente a volver a su celda; mientras la educadora de la unidad trataba de hablar con él para proponerle una cita en la que poder charlar, los reiterados insultos del menor hacia los vigilantes dieron lugar a una demanda de "refuerzos"; la educadora se colocó entonces en un segundo plano, como si hubiera pasado su turno, para no volver a intervenir hasta que el incidente ya había sido "controlado" por los vigilantes penitenciarios:

\footnotetext{
Dos nuevos vigilantes entran en la celda y Jilal se pone aún más nervioso: $Y$ vosotros, ¿qué hacéis? ¿Me tomáis por un ladrón, verdad? Venga, piraos". Uno de los vigilantes le coge entonces del brazo para volver a meterlo en la celda. El menor forcejea, cada uno de los vigilantes coge una pierna o un brazo, el joven grita, se resiste. Lo ponen en el suelo, hacen sonar la alarma y lo inmovilizan. Llegan unos diez vigilantes más: “¿Qué está pasando aquí?" Cuando lo meten en la celda, el teniente dice: "Vale, confinamiento todo el fin de semana". La educadora piensa que este incidente puede servir al menor para "reflexionar sobre sus actos". "Hay que dejarlo reflexionar un poco. En fin, he hablado con él a través de los barrotes y le he dicho: 'ahora te toca reflexionar sobre tus actos, tu reacción ha sido desmesurada y debes asumir las consecuencias'. Yo soy así con ellos, ¿̇sabes? Hay que devolverlos a la realidad. Las cosas son así, no se les puede dejar pasar una. iLos educadores no podemos estar aquí para decorar, de eso nada, nuestro papel también consiste en recordarles dónde están, por qué están aquí y cuáles son las reglas! (Diario de campo)
}

Durante estas típicas escenas de interacciones, ya no se trata solo de legitimar el carácter aflictivo de la pena como condición sine qua non de una toma de conciencia por parte del infractor respecto a la grave-

[ 38 ] GILLES ChANTRAINE, NICOLAS SALLÉE

SIPS - PEDAGOGIA SOCIAL. REVISTA INTERUNIVERSITARIA [1139-1723 (2013) 22, 29-42] TERCERA ÉPOCA 
dad de las infracciones cometidas; tampoco se trata ya únicamente de constreñir al menor a una conversación en la que confiese y exprese sus sentimientos a los profesionales. Como es intangible y la configuración de las relaciones de fuerza entre profesionales impide cualquier forma de innovación, de lo que también se trata, aunque solo sea por legitimar su presencia en el espacio de reclusión, es de legitimar la pertinencia del orden penitenciario y su sistema de sanciones. La "responsabilización" es, por lo tanto, una responsabilización tan penal como penitenciaria. Pese a la enorme artificialidad de la organización de la prisión respecto al exterior, el respeto del reglamento tiende a convertirse aquí en un criterio principal y a veces único del éxito educativo del EPM. Los educadores cargan entonces sobre las espaldas del menor el peso de su propia incapacidad para cambiar el marco securitario del establecimiento.

\section{Conclusión}

La particularidad de los EPM dentro del sistema penitenciario francés reside en el hecho de que, en ellos, los vigilantes se ven más forzados a poner en tela de juicio las habilidades penitenciarias tradicionales. Y esto es así al menos por tres razones. Para empezar, porque no pueden ignorar totalmente la especificidad del estatus de minoría de edad del público al que deben vigilar. Después (y sobre todo) porque sus prácticas cotidianas están más sometidas a la mirada de otros profesionales que no pertenecen a la administración penitenciaria. Por último, porque como contrapartida se ven confrontados a la multiplicidad de percepciones que de los presos tienen otros profesionales (para los educadores PJJ, los menores son ciertamente presos, pero también, precisamente, "jóvenes", "adolescentes", "chavales" e, incluso, "niños"); una multiplicidad que desnaturaliza la evidencia de las respuestas securitarias, sobre todo respecto a las sanciones a las que se suele tratar de buscar un carácter constructivo más allá de su función de producción de orden.

En ellos, por lo tanto, el empeño de producir orden mejorando la calidad del vínculo social (diálogo, escucha, negociación) se desarrolla, asume e, incluso, reivindica más; adopta, sobre todo, una coloración "educativa" que refuerza en los agentes penitenciarios el sentimiento de que su profesión tiene un sentido más allá de la reclusión. Por todas estas razones, los EPM parecen representar una forma avanzada de la destotalitarización de la institución carcelaria ${ }^{15}$, gracias a una mayor aceptación de la complejidad social y humana de la adolescencia desviada y, por ende, al rechazo de reducir al joven a su estatus de preso.

Este movimiento es, no obstante, paradójico. Se apoya efectivamente en un continuum punitivo sofisticado que articula medidas infradisciplinarias de buen orden, cuya supuesta eficacia reside en la inmediatez de su puesta en marcha y en la flexibilidad de su manejo, con procedimientos disciplinarios clásicos, algunas veces reivindicados como "educativos" pero cuya aplicación sigue siendo una prerrogativa celosamente reservada a la administración penitenciaria y capaces de conducir a penas tan brutales como el ingreso en un módulo disciplinario. En cierta medida, el EPM reúne las constricciones flexibles características de las instituciones educativas no carcelarias, como un centro de acogida, y la rigidez reglamentaria de la prisión. La postura adoptada por numerosos educadores PJJ en un EPM simboliza este movimiento paradójico. Si bien los educadores participan efectivamente en un proceso de apertura de la prisión hacia el exterior cuando se dedican a la construcción de trayectorias individuales extramuros, la mayoría de ellos también trata de legitimar su presencia intramuros naturalizando las constricciones penitenciarias. El concepto de educación responsabilizadora actúa entonces como un recurso pragmático, generalmente movilizado a posteriori, que permite a los educadores defender su monopolio en la acción educativa al mismo tiempo que delegan las tareas de mantenimiento del orden a los únicos auténticos representantes del orden carcelario: los vigilantes penitenciarios. Esta posición específica viene así a completar la acción de los vigilantes: ya no se trata únicamente de constreñir los cuerpos de los presos a someterse al orden penitenciario, sino también de trabajar en pos de una movilización de las subjetividades reclusas mediante un trabajo de persuasión sobre la pertinencia del orden penitenciario. El EPM realizaría así, por un ardid de la historia, la utopía disciplinaria. 


\section{Referencias bibliográficas}

Aubusson de Cavarlay, B. (1999). France 1998. "La justice des mineurs bousculée", Criminologie, 32 (2), 83-99.

Bajoit, G. (1988). Exit, voice, loyalty... and apathy. Les réactions individuelles au mécontentement, Revue française de sociologie, 29 (2), 325-345.

Botbol, M. y Choquet, L.C., (2010). Le “faire-avec" les mineurs délinquants dans l'action éducative. En S. Abdellaoui, (coord.), Les jeunes et la loi. Nouvelles transgressions? Nouvelles pratiques? París: L'Harmattan.

Chantraine, G. (2000). La sociologie carcérale: approche et débats théoriques en France, Déviance et Société, 24 (3), $297-318$.

Chantraine, G. (2004). Par-delà les murs. Expériences et trajectoires en maison d'arrêt. París: PUF.

Chantraine, G., (Dir.); Sallée, N.; Scheer, D.; Salle, G.; Franssen, A. y Cliquennois, G. (2011). Les prisons pour mineurs. Controverses sociales, pratiques professionnelles, expériences de réclusion. Informe para el proyecto de investigación Droit et Justice, CleRsé.

Chauvenet, A. (1996). L'échange et la prison. En C. Faugeron,; A. Chauvenet, y P. Combessie, (coord.). Approches de la prison. (pp.45-70). Bruxelles: Universidad De Boeck

Chauvenet, A.; Benguigui, G. y Orlic, F. (1993). Les surveillants de prison: le prix de la sécurité, Revue française de sociologie, 34 (3), 345-366.

Crewe, B. (2009). The Prisonner Society. Prison, Adaptation, and Social Life in an English Prison. Oxford: Oxford University Press, Clarendon Studies in Criminology.

Daumas, J.L. y Palacio, M. (1998). Le droit à une éducation sans restriction. Les cahiers dynamiques, 12, 17-22.

Faugeron, C. y Le Buolaire, J.M. (1992). Prisons, peines de prison et ordre public, Revue française de sociologie, 33 (1), 3-32.

La Clecla, F. (2002). Le malentendu. París: Balland.

Liebling, A. y Price, D. (2001). The Prison Officer. Winchester: Waterside Press.

Liebling, A. (2000). Prisons officers, Policing and the Use of Discretion. Theoretical Criminology, 4 (3), 333-357.

Milburn, P. (2009). Quelle justice pour les mineurs? Entre enfance menacée et adolescence menaçante. Toulouse: Erès.

Mucchielli, L. (2010). L'évolution de la délinquance des mineurs. Entre criminalisation, judiciarisation et ghettoïsation. En M. Boucher (coord.). Penser les questions sociales et culturelles contemporaines: Quels enjeux pour l'intervention sociale? (pp.103-130). París: L'Harmattan.

Mucchielli, L. (2000). L'expertise policière de la 'violence urbaine', sa construction intellectuelle et ses usages dans le débat public français. Déviance et société, 24 (4), 351-375.

Peyronnet, J.C. y Pillet, F. (2011). Rapport d'information sur l'enfermement des mineurs: évaluation des centres éducatifs fermés et des établissements pénitentiaires pour mineurs. Paris: Sénat.

Robert, P. y Pottier M.L. (2004). Les préoccupations sécuritaires: une mutation?. Revue française de sociologie, 45 (2), $211-241$.

Salle, G. y Chantraine, G. (2009). Le droit emprisonné? Sociologie des usages sociaux du droit en prison. Politix, 87 (3), $93-117$.

Sallée, N. (2009). Une clinique de l'ordre. Examen des controverses autour de l'ordonnance du 2 février 1945. Vacarme, 49, 25-27

Sallée, N. (2010). Les éducateurs de la Protection Judiciaire de la Jeunesse à l'épreuve de l'évolution du traitement pénal des mineurs délinquants. Champ pénal/Penal field, 7, Recuperado de http://champpenal.revues.org/7756.

Sallée, N. (2012). Des éducateurs placés sous main de justice. Les éducateurs de la Protection judiciaire de la jeunesse entre droit pénal et savoirs sur l'homme. (Tesis doctoral). Universidad París Oeste Nanterre: Nanterre, Francia.

Sicot, F. (2009). Une reconfiguration du traitement des déviances juvéniles au tournant des années 1990: vers un accroissement généralisé de l'encadrement. En A. Stora-Lamarre, J.C. Caron y J.J. Yvorel, (coord.), Les âmes mal-nées. Jeunesse et délinquance urbaine en France et en Europe (19e-21e siècles). (pp.299-313), Besançon: Presses universitaires de Franche-Comté.

Youf, D. (2000). Repenser le droit pénal des mineurs. Esprit, 10, 87-112.

[ 40 ] GILlES ChANTRAINE, NICOLAS SALLÉE

SIPS - PEDAGOGIA SOCIAL. REVISTA INTERUNIVERSITARIA [1139-1723 (2013) 22, 29-42] TERCERA ÉPOCA 


\section{Notas}

1 Módulos destinados a los menores en las cárceles para adultos [N. de la T.].

2 Aunque la apertura de 6 EPM desde el año 2008 permitió cerrar algunos quartiers mineurs, hoy coexisten las dos formas de encarcelamiento. El primero de junio de 2012, los 6 EPM contaban con 265 presos varones y 10 mujeres, frente a los 444 varones y 21 mujeres encarcelados en los 45 quartiers mineurs.

3 Todos los EPM se componen de 7 unidades de vida, con un máximo de 10 menores presos en cada una. Una de ellas está reservada a los presos "recién llegados" y en ella permanecen durante una semana, en "observación", antes de ser destinados a una de las seis unidades restantes. La elección de este destino se discute y decide en las reuniones denominadas "CPU", esto es, "comisiones pluridisciplinares únicas", en las que se juntan vigilantes, educadores, profesores y, de forma no obstante más aleatoria, personal sanitario.

4 Esta conminación figura en la Ley Perben I de 9 de septiembre de 2002, "de orientación y de programación para la justicia".

5 Investigación realizada con el apoyo del GIP, Mission de Recherche Droit et Justice.

6 Según los informes de actividad de estos dos EPM relativos al año 2009, la gran mayoría de los menores está encarcelada en el marco de procedimientos correccionales (90\%, frente al 10\% que lo están en el marco de procedimientos criminales), principalmente por hechos de hurto o robo con fuerza (prácticamente el 50\% de los menores encarcelados), más raramente por hechos violentos (15\% más o menos). La violación (menos del 5\%) o el asesinato (menos del 3\%) son claramente minoritarios. Además, alrededor del 60\% de los menores presos son preventivos y se encuentran, por lo tanto, a la espera de juicio, y el 40\% son condenados. La duración media de reclusión de un menor es de dos meses y medio.

7 Este descenso es significativamente consecutivo al voto de dos leyes, en 1987 y 1989, que apuntaban a limitar la prisión provisional de los menores.

8 En el planteamiento de estos argumentos, cabe destacar a Manuel Palacio, conocido en el DPJJ por haber sido el defensor, en su calidad de director, a finales de 1990, de la oficina de métodos y acción educativa del DPJJ, del proyecto de apertura de los centros educativos de acogimiento residencial basados en el uso de la constricción y la contención.

9 Esta concepción educativa se asienta en una representación de los jóvenes delincuentes en tanto seres a quienes "hacer responsables", y bebe fundamentalmente de la fuerte influencia en la PJJ de las reflexiones de Pierre Legendre sobre los lazos entre derecho y psicoanálisis (1992) durante la década de 1990 (Sallée, 2010; 2012). Esta lectura permite poner en primer plano la necesidad de los educadores de restablecer en la mente de los menores delincuentes un orden simbólico basado en la limitación de sus deseos inconscientes de omnipotencia.

10 La importancia para los vigilantes de recurrir a formas de negociación en torno a las reglas, en la producción cotidiana del orden carcelario es un resultado relativamente clásico en sociología de la prisión (Chauvenet et al. 1993; Chauvenet, 1996; Liebling, 2000; Liebling y Price, 2001; Chantraine, 2004; Crewe, 2009).

${ }^{11}$ Los autores hablan respectivamente de centres de détention (para presos preventivos o condenados a penas de cárcel inferiores o iguales a un año) y de maisons centrales (cárceles para condenados a más de un año de prisión), cárceles que se corresponden relativamente (la coincidencia nunca es total dadas las diferencias entre las legislaciones penales y penitenciarias de los diferentes estados) en el estado español con las cárceles de preventivos (reclusos en espera de juicio o condenados a penas de cárcel iguales o inferiores a 6 meses) y cárceles de cumplimiento (para presos con penas privativas de libertad superiores a 6 meses) [N. de la T.].

12 Previo a un procedimiento disciplinario, el uso del informe de incidente resulta ambivalente: si bien es una amenaza potencial para los presos, utilizado con demasiada frecuencia o de forma "inadecuada" puede asimismo desacreditar al vigilante tanto ante los menores como antes los colegas, al poner de manifiesto su incapacidad de gestionar por si solo los problemas de la reclusión así como su incapacidad de ganarse, imponer y mantener el "respeto" de los reclusos.

13 La acumulación de castigos infradisciplinarios y disciplinarios en prisión (Sallée, Chantraine, 2009, p. 115) constituye la estrategia complementaria a la elusión de procedimientos disciplinarios. Juntas, ambas estrategias ofrecen un panel punitivo muy diverso, que vuelve además inoperante, para el observador, la diferencia entre derecho y no derecho, en la observación de los usos sociales del derecho en situación de reclusión.

14 Guy Bajoit quiso completar el modelo inicialmente propuesto por el economista Albert Hirschman (1972). El comportamiento de "lealtad" (loyalty) propuesto por Hirschman como alternativa a los comportamientos de "protesta" (voice) y fuga (exit) no permitía comprender, de acuerdo a Bajoit, las frecuentes actitudes de "resignación" y "participación pasiva" adoptadas frente al descontento.

15 Para una presentación de los trabajos sociológicos que versan sobre este proceso de "destotalitarización", véase Chantraine (2000). 


\section{Dirección de los autores}

Gilles Chantraine. Centre Lillois d'Etudes et de Recherches Sociologiques et Economiques. Faculté des Sciences Economiques et Sociales. Université Lille 1, Cité Scientifique, 59100 Lille, Francia.

Nicolas Sallée. Université Paris Ouest Nanterre. Maison Max Weber. Bâtiment T. 200 Avenue de la République, 92000 Nanterre, Francia.

Correo electrónico: gilleschantraine@gmail.com, nicolas.sallee@gmail.com

Fecha de recepción del artículo: 11.2.2013

Fecha de revisión del artículo: 6.3.2013

Fecha de aceptación final: 25.4.2013

\section{Cómo citar este artículo}

Chantraine, G. y Sallée, N. (2013). La educación puesta a prueba en un espacio de reclusión. Pedagogía Social. Revista Interuniversitaria, 22, pp-pp. 29-42

[ 42 ] GILles ChANTRAINE, NICOLAS SALLÉE

SIPS - PEDAGOGIA SOCIAL. REVISTA INTERUNIVERSITARIA [1139-1723 (2013) 22, 29-42] TERCERA ÉPOCA 